\title{
A relação com os seres espirituais na festa Garpiéhj Náe entre os Ikólóéhj Gavião de Rondônia
}

\author{
Iram Káv Sona Gavião ${ }^{1}$
}

\begin{abstract}
Resumo
Desde o início da invasão neste continente ameríndio, todas as sociedades originárias sofreram um impacto muito grande na sua língua, cultura e religião. Assim também aconteceu com o povo Ikólóéhj Gavião. Os não indígenas não só invadiram a nossa terra, como também invadiram a nossa cultura. Por isso, para mim e para o meu povo, o tema "festas tradicionais" é fundamental para entender a importância desta prática como um momento de fortalecimento da união, reciprocidade, solidariedade e harmonia entre seres humanos e seres espirituais. Neste artigo, descrevo sucintamente a festa Garpiéhj Náe para levar ao conhecimento das novas gerações Ikólóehj, que não a vivenciaram, e da sociedade não indígena que já passa mais de quinhentos anos impondo suas práticas culturais aos povos originários do país que foi chamado Brasil, como se estes povos não tivessem cultura.
\end{abstract}

Palavras-chave: Povo Gavião Ikólóehj; Ritual; Festa Garpiéhj Náe.

\section{Resumen}

Desde el inicio de la invasión en este continente ameríndio, todas las sociedades originarias sufrieram un impacto muy grande en su lengua, cultura y religión. Lo mismo ocurrió con el pueblo Ikólóéhj Gavião. Los no indígenas no solo invadieron nuestra tierra, como tambiém invadieron a nuestra cultura. Por ello, para mí y para o mi pueblo, el tema de las "fiestas tradicionales" es fundamental para entender la importancia de esta práctica como un momento de fortalecimiento de la unión, reciprocidad, solidaridad y armonía entre seres humanos y seres espirituales. En este artículo, describo sucintamente la fiesta Garpiéhj Náe para llevar al conhecimento de las nuevas generaciones Ikólóehj, que no la vivieron, y de la sociedad no indígena que ya pasa más de quinientos años imponiendo sus prácticas

\footnotetext{
1 Pertenço ao Povo Ikólóéhj (traduzido significa Gavião), moro na aldeia Ikólóéhj, localizada na Terra Indígena Igarapé Lourdes em Ji-Paraná, Rondônia. Minha língua materna é Ikólóéhj, sou falante com orgulho. Aprendi a ler e escrever na minha língua e, por isso, fui logo convidado a lecionar na aldeia. Passei pelo projeto de formação de professores indígenas de Rondônia entre 1998 e 2004. Com a conquista do curso de Licenciatura em Educação Básica Intercultural na Universidade Federal de Rondônia ingressei na primeira turma concluindo em 2015. Aprovado na seleção para mestrado em Linguística na Universidade de Brasília trabalhei na descrição da língua Ikólóéhj. Atualmente trabalho Língua Materna e História com alunos Ikólóéhj. Assim, sigo minha luta em prol do meu povo.
} 
culturales a los pueblos originarios del país que nombraron Brasil, como si estos pueblos no tuvieran cultura.

Palavras-chave: Povo Gavião Ikólóehj; Ritual; Festa Garpiéhj Náe.

\section{Introdução}

Percebendo a importância das festas para união do povo Ikólóéhj, passei a pesquisar as festas para entender as bases da organização social do povo². Entendo que as festas eram a motivação para o povo se reunir e realizar qualquer outra atividade. Assim, o tempo gasto era reduzido e o esforço físico também. Com o passar do tempo, com o contato com a sociedade envolvente e a interferência da religião importada, essa prática vem sendo desprezada pela comunidade. Assim, os vaváhej ${ }^{3}$ ou pajés, que eram os condutores das festas e protetores das suas comunidades, deixaram de exercer o seu papel dentro da aldeia. Eles que eram figuras respeitadas foram colocados de lado, como qualquer pessoa simples, sem importância. Atualmente, as suas práticas são ignoradas e eles são criticados, humilhados pelas pessoas que pregam o evangelho na aldeia, fazendo com que se envergonhem do próprio trabalho. Assim, eles próprios deixaram e desistiram de praticar o seu trabalho na comunidade. Dessa maneira, os jovens e as novas gerações desconhecem seu papel na preservação de sua cultura, e as festas correm o risco de desaparecer se não forem retomadas pelo povo.

Realizei minha pesquisa em quatro aldeias localizadas ao sul da Terra Indígena Igarapé Lourdes, localizada em Rondônia, entrevistando os principais conhecedores da festa que moram nestas aldeias. Eu usei os conhecimentos destes colaboradores porque eles presenciaram e participaram da festa que eu queria descrever. Contei, também, com informações que tinha na memória a partir de conversas com meu finado avô, Digüt, importante liderança do povo. A partir das entrevistas, decidi falar somente da festa Garpiéhj Náe que é a mais significativa para o povo e também a mais complexa, pois envolve a presença dos seres espirituais, tendo como alguns dos objetivos trazerem mais caças para aldeia e reivindicar o controle do tempo (estações). Além disso, é uma festa que incorpora outras duas festas: festa de derrubada e festa de construção, que são realizadas no decorrer da preparação da festa central. Estas duas festas também foram pesquisadas, porém são descritas apenas brevemente aqui.

\footnotetext{
${ }^{2}$ Este artigo é baseado em uma parte do resultado de um trabalho de conclusão de curso, realizado em 2015, sobre festas tradicionais do povo Ikólóéhj Gavião.

3 O texto contém várias palavras e expressões na língua Ikólóéhj que são importantes para a compreensão do ritual que descrevo aqui. No geral, essas palavras vêm seguidas da tradução ou explicação do significado.
} 


\section{Quem somos}

Muito antes do contato com os colonizadores que vinham chegando e ocupando territórios indígenas, historicamente o povo Ikólóéhj Gavião habitava a margem do Rio Branco, no atual Estado de Mato Grosso. Os velhos relatam que é de lá que nós viemos, fugindo do conflito com outros povos rivais que frequentemente nos atacavam, ou por motivo de existir uma pessoa malíssima, chamada Tihn, que aprontava e matava as pessoas de seu próprio povo, a quem as comunidades resolveram deixar e abandonar. Este é o primeiro motivo que levou os Ikólóéhj a abandonar seu primeiro território tradicional até chegar ao território atual. Antigamente, o território do povo Ikólóéhj, hoje fazenda, era marcado através de aldeamento, história, mitos, ritos e os vestígios deixados na região durante sua ocupação. Cada grupo ou família formavam suas aldeias para aquela terra pertencer a eles futuramente. Não existia demarcação nessa época. Só sabiam que as aldeias e os locais onde caçavam pertenciam a eles. Então, aquela área era seu pertencimento.

$\mathrm{O}$ atrito frequente que eles vinham sofrendo por parte dos povos vizinhos os levou a abandonar suas aldeias à procura de lugar seguro para o seu povo. Durante este percurso, os Ikólóéhj entraram em contato com o povo Vitíguréhj ${ }^{4}$ Arara, através dos quais contataram o homem branco, pois estes já tinham conhecido os brancos.

Nos autodenominamos Ikólóéhj, termo que em nossa língua significa gavião. Portanto, também somos conhecidos como Gavião. Somos falantes de uma língua da família Tupi-Mondé. Habitamos a bacia do igarapé Lourdes e outros afluentes do rio Machado (ou Ji-Paraná), no estado de Rondônia, próximo à divisa com o Mato Grosso. Vivemos na Terra Indígena Igarapé Lourdes com uma população de aproximadamente 800 pessoas, distribuídas em dezesseis aldeias, todas elas localizadas no interior desta Terra Indígena que compartilhamos com um outro grupo indígena, os Karo Arara.

\section{Sobre a festa Garpiéhj Náe e os seres espirituais}

Uma das festas mais importantes do povo Ikólóéhj é a festa Garpiéhj Náe, a festa dos seres do céu, pois considera os moradores do Garpi (céu) os seres sobrenaturais desse planeta, que são os donos espirituais da natureza que habitam o céu. Nessa festa são convidados vários seres espirituais como Korkoróh Tìh (espírito do gavião), Bebeéhj Tìh (espírito dos porcos queixadas), Gorá (Criador, Deus), Bákóhvà Tìh (espírito da coruja), Íraláh Tìh (espírito do japú), Majakóh Tìh

\footnotetext{
${ }^{4}$ Modo como os Ikólóéhj nomeiam o povo Karo Arara, pois quando viram os Arara pela primeira vez, se surpreenderam com a enorme quantidade de batatas que eles produziam. A palavra Vitíguréhj significa batateiros ou povo da batata.
} 
(espírito do urubu), entre outros. É o pajé, que nós chamamos de vavaáh, junto com Zagapóhj, o seu guia-protetor, que convida os seres espirituais levando informações e divulgando essa festa para o Garpi. Eles levam as reivindicações do madjaj, dono da festa, para os seres espirituais do Garpi dizendo que está sendo realizada uma grande festa e muito ì sòhn, (chicha azeda) para ser consumida durante a festa. E pede doação dos porcos a pedido do madjaj. Em troca os espíritos pedem muito ì sòhn, e quem come carne como o Korkoróh Tìh, espírito do Gavião e Gojbíhr Tìh, espírito do marimbondo, encomenda muita caça para ele. E na ocasião da festa eles atendem ao convite e vem para festejar. Então, eles chegam e se apresentam incorporados na figura do vạváh.

O objetivo do Garpiéhj Náe é pedir dos Garpiéhj que eles façam o ano correr bem e, ao mesmo tempo, solicitar a eles que mandem de lá, do Garpi, muitos bebeéhj (porcões), os bebeéhj que eles criam no céu. Sorabáh, um dos mais antigos, falou que o povo Ikólóéhj Gavião, quando ouvia o estrondo de trovão no Garpi acreditava que o ano não correria tão bem. Por isso, essa festa era realizada para trazerem os seres divinos para propor suas reivindicações a eles ${ }^{5}$. Acreditamos que esses seres divinos que moram no céu, no Garpi, cuidam da natureza e de nós seres humanos, ou seja, do planeta. Portanto, essa festa era realizada no início do período seco que corresponde aos meses de maio a outubro. Quando o djókángáv (murici) floresce já é o início do gávo (estação seca). Era assim que os antigos reconheciam quando esta estação chegava.

Esta festa era realizada quando os estrondos de trovão e a chuva se estendiam mais do que o previsto. O povo ficava preocupado que a estação seca não ocorreria tão bem e que o ano passaria mais rápido do que de costume. Assim, se fazia a festa para reivindicar aos Garpiéhj um bom tempo de seca, um bom ano, y por isso as pessoas dialogavam com o espírito no momento em que ele estivesse se apresentando incorporado no vaváh, pedindo o bom tempo, saúde, proteção e o equilíbrio do tempo.

Por outro lado, essa festa também era uma forma de propor suas reivindicações à esses seres divinos, pedindo uma caça farta, especialmente de bebeéhj (porcões do mato). Na ocasião de convite da festa, o vạváh levava a reivindicação do dono da festa para os donos das criações (porcos queixadas), enquanto os convidados, Garpiéhj, ofereciam sua criação (seus animais). Neste momento do convite, o vạváh já fazia a encomenda de quais espécies de porcos ele queria. Porém, existe no Garpi o Amóa Tì (espírito do jabuti), que é um imenso jabuti que fica deitado na porta do chiqueiro como um guardião, impedindo que os porcões saiam. Então, os porcos que conseguem passar pelo Amóa Tìh, são aqueles

\footnotetext{
${ }^{5}$ Para nós, o ano corresponde ao período que vai do início da seca até o início da chuva.
} 
que conseguem chegar aqui, na terra, e são os mesmos que foram encomendados pelo vavaáh. Assim, durante a festa, era feita a entrega dessa encomenda para o vạváh na forma de muitas caças atraídas para as proximidades da aldeia.

As escolhas do vavaáh na ocasião do convite são importantes porque para os Ikólóéhj há diferentes espécies de bebeéhj. Existem, por exemplo porcos do Ixía tìh, do espírito da pedra. Se eles chegam à aldeia e o pessoal os flecha, eles não morrem fácil, eles são duros de morrer, portanto, essa espécie não será escolhida pelo vavaáh. Ainda há porcos ferozes que são uma porcão do espírito Talóder. Essa espécie é muito perigosa, então, o vavaáh também não deve escolhê-la. Tem uma história que fala que esta espécie foi escolhida pelo vaváh para ser trazida para aldeia. Quando percebeu o bando de porcos chegando, os caçadores foram atrás deles para matar. Aproximando-se deles, eles começaram a atirar. Os porcos não queriam correr, pois eram bravos, ariscos. Em vez de correr, eles vinham para cima dos caçadores para morder. Assim aconteceu com um homem Gavião. Os porcos vieram atacá-lo e morderam sua face e sua garganta. Por isso, o vavaáh não deve escolher essa espécie. Há o porcão do Bákóhvà Tìh, o espírito da coruja, e o do Majakóh Tì, espírito de urubu, que podem ser escolhidos, pois são mansos, não enfrentam caçadores. Segundo Alberto Padág Gavião, os porcos do Ibíhr TunTun, espírito de pássaros de igarapézinho, são porcos comuns que sempre vemos, são daqui, da terra mesmo, e podem ser flechados. E há outros tipos mais.

Para essa festa eram erguidos dois postes, Gáhrà (um poste representando o feminino e outro o masculino), onde o vavaáh amarrava as crianças com fibra de buriti para simular os porcos que ficam no Gáhrà. Estes simbolizavam os animais de criação que existem no céu. As crianças ficavam no pé deste poste durante o tempo que o vaváh dançava com os espíritos. Esse gesto era uma simulação de que o vavaáh estava recebendo a criação oferecida pelos Garpiéhj e de que os porcos estarão amarrados no pé deste Gáhrà, o que as crianças (meninas e meninos) representavam.

Durante o ritual executado pelo vạaáh, algumas proibições e regras são impostas ao povo. Uma destas proibições consiste em que as pessoas não devem participar da festa após terem tido relações sexuais. As mulheres que tem crianças pequenas não devem ficar andando livremente nestes dias, pois os espíritos estarão por ali. Se as crianças estiverem andando por ali podem levar choque dos espíritos que pode fazer mal às crianças. As almas das crianças podem ser sequestradas por eles, o que pode levar a criança à morte. Só o vaváh pode resgatar a alma e trazer ela de volta para que as pessoas vivam novamente. Outra proibição é a presença das mulheres menstruadas durante a cerimônia. É necessário evitar bagunças, brigas e não devem queimar as coisas de mau cheiro 
que desagradam o espírito que estiver presente naquele momento, para não interromper o zérégòhj dos porcos e evitar desmaio do vavaáh, pois neste momento ele está cheio de energia dos espíritos. O zérégòhj é uma linha invisível que interliga o gáhrà do Garpi ao gàhra da aldeia, é uma espécie de teia invisível onde as criações estão amarradas. Se alguém tocar o vaváh, ele pode levar choque, ataque que pode levar ao desmaio ou até a morte se o outro vavaáh não estiver por ali. Somente um vạváh pode curar outro quando este leva um choque. Os Garpiéhj não gostam de bagunça ou de sentir qualquer cheiro que eles desconheçam. Durante o ritual, o zérégòhj interliga o vavaáh aos Garpiéhj. No entanto, é somente o vavaáh que vê esta teia. É ela que faz a ligação do vavaáh com os Garpiéhj. Caso alguém tenha relações sexuais, se uma mulher menstruada estiver no meio da festa, ou ainda se os participantes da festa dançarem de uma maneira inadequada, essa teia será rompida e o ritual não terá o efeito desejado. É através do zérégòhj que os porcos que foram doados pelos Garpiéhj chegam até a aldeia. Por isso, o vạváh recomenda aos caçadores não matarem os porcos antes do término da festa. Os porcos tem que ficar perto da aldeia pra se acostumar com o local. Se os primeiros porcos que chegarem à aldeia forem caçados imediatamente, os demais que estavam se aproximando fogem e o zérégòhj é rompido. É por meio do seu zérégòhj que os porcos vêm chegando. Mas se eles percebem que estão sendo caçados exageradamente, eles recuam e desistem de se aproximar da aldeia. As crianças amarradas no Gáhrà são um sinal de que os porcos estarão amarrados ali. Por isso, eles vem atrás do seu zérégòhj que está ligado no Gáhrà, à procura dessa simulação.

Assim que os porcos são caçados, durante a festa ou posteriormente, os caçadores devem trazer a caça para o vavạ́h executar o póá (ritual de assoprar fumaça de tabaco) sobre os porcos, para evitar que o espírito deste porco faça mal e leve a alma do caçador ou das demais pessoas. É a maneira de afastar a força do espírito para que ela não ataque as pessoas. É um diálogo espiritual com o dono dos porcos, também para que ele mantenha os porcos nas proximidades da aldeia. Este gesto também demonstra respeito pelo vavaáh e pelos donos dos porcos que são os Garpiéhj presentes na festa. No caso, se os porcos foram mortos, os caçadores devem dar um para o vaváh para pagar o serviço que ele teve de trazer para a aldeia, pois ele que tomará conta das criações que os criadores tinham que trazer do Garpi, do céu. Os porcos que foram doados, ficarão na responsabilidade dele e ele será o dono destes porcos, será a referência para eles. Por isso, o vaváh avisava as pessoas dizendo que as caças chegarão hoje na aldeia, encomendava para os caçadores matarem a caça para o povo e ele já sabia que naquele dia o bando de porcos varava na aldeia. 


\section{A realização da festa}

Assim, a festa realizada pelo povo Ikólóéhj Gavião não era uma festa realizada de um dia para o outro. Como vimos, é um processo muito longo que precisa de muita dedicação para acontecer. Vimos que, durante os preparativos, ocorrem várias atividades em que era preciso realizar uma pequena festa para trazer as pessoas para fazer o trabalho. A primeira coisa que a pessoa que desejava convocar a festa devia fazer era preparar a roça; ele devia roçar as partes mais baixas da floresta para depois derrubar. O próprio dono da roça iniciava a derrubada. Quando a roça estava pela metade, ele deixava de derrubar para que as pessoas que ele iria convidar, terminassem de derrubar para ele. O serviço era feito em reciprocidade, solidariedade e harmonia. Quando chegava o mês em que a roça devia ser queimada, era usado o conhecimento dos seus ancestrais para que a roça se queimasse bem, pois dizem que antigamente um homem era casado com a mulher-urubu e, quando chegava a época de tocar fogo na roça, o pai do urubu fazia ventar para que a roça dela se queimasse bem limpo. Quando caía a primeira chuva ou quando chegava o fim da seca, o plantio era realizado. Assim que a roça já estava produzindo, a atividade de colheita acontecia com o pedido do dono, acompanhada da festa. A festa começava a ser divulgada. O madjaj informava para o vavaáh o desejo de realizar uma festa para os Garpiéhj, os seres espirituais do Garpi, o céu. Ele concordava. O madjaj, o chefe da festa se auto denominava com outro novo nome. Escolhia também o nome da sua chicha. Para a realização da festa, é necessário escolher o seu parceiro (Bapi) de confiança para te ajudar na organização e realização. Ele faz visita em cada aldeia divulgando sua festa e distribuindo convite juntos com seus parceiros. O convite era feito ao vivo. $\mathrm{O}$ diálogo informal é muito demorado, exige muita sabedoria para levar a conversa. Havia muitas encomendas neste momento. Enquanto isso, vavaáh, junto com Zagapóhj o seu guia protetor, faziam suas viagens espirituais para convidarem os seres de outro mundo levando reivindicação do madjaj (chefe da festa). Zav póhj (maloca) era construída para abrigar os convidados e para pôr os akabíh (pilões) de armazenamento do ì sònhn (chicha azeda). Esse trabalho também exigia uma festa para ser realizada. Segundo Sorabáh, um dos mais velhos, que presenciou a atividade de construção da maloca, era também preciso um acompanhamento do líder espiritual, vaváh (pajé), para protegerem os trabalhadores no serviço. O vaváh ficava incorporado com o Íraláh Tìn ${ }^{6}$ (espírito de japú), fazendo simulação deste enquanto a casa estava sendo construída. O íraláh é um pássaro construtor

${ }^{6}$ Este pássaro é conhecido como Guacho ou Japu, aquele que faz seu ninho pendurado nos galhos das árvores. 
do ninho e por isso ele deve acompanhar a realização de cobertura da maloca para que seja bem feita. O ì sòhn, chicha azeda, era produzida pouco a pouco para ser consumida nas atividades de preparo, sendo responsabilidade da mulher do madjaj. Ela designava outras mulheres para serem matíhréhj dela, um tipo de empregadas. As mulheres são responsáveis pelo preparativo da chicha. São elas que buscam xíbòjà (mandioca), mojạ (cará), vitíhgà (batata) e ma'eg (milho) da roça. São elas que ajudam na distribuição do ì sònhn quando chegam visitas ou no dia da festa. Elas são pessoas fundamentais para a festa acontecer, pois sem a chicha não haveria festa. Sem elas não há chicha e nem alimentação. Elas também ajudam nos cuidados das pessoas quando elas ficam embriagadas, seguram os braços dos embriagados para não caírem e levam para rede para eles dormirem. Elas são consideradas também como espécies de madjaj, pessoas que são ajudantes do dono da festa.

As comunidades de várias aldeias realizam o táhná. Cada dia ou cada semana chegam novas visitas para tomar chicha. Quando a festa está para acontecer, o madjaj, o anfitrião, realiza um último aviso aos convidados que a festa está chegando ao seu auge e que precisa ser encerrada. É o momento das pessoas se deslocarem da sua aldeia para a festa. As pessoas chegam com caças moqueadas e as deixam no bekáh, no local onde os dançarinos se arrumam para festa. O vaváh incorporado com o Korkoróh Tìh (espírito do gavião), por quem essa caça foi encomendada, vai até o bekáh para receber o magàhj (carne moqueada). Vai cantando e perguntando um por um se este matou a caça para ele. Junto com ele vão outras pessoas com paneiro para coletar as carnes. O vaváh vai enchendo cada paneiro de carne. Este é trazido para casa para ser consumido pelo Bebeéhj Tìh (espírito dos porcos), Korkoróh Tì (espírito do gavião) e atirado no momento do ritual em que repassam as sortes para os caçadores através do espírito do boráhr. O boráhr é uma planta que geralmente é utilizada e passada no corpo dos caçadores para dar sorte na caçada ou atrair mais caças. No caso deste ritual, o boráhr não é passado no corpo e sim o espírito do boráhr é que está presente na festa e tem o significado de transmitir sorte aos caçadores para as caçadas.

Falamos, inicialmente, que a festa era realizada para que o ano corresse bem. Também era importante convidar, trazer os seres Garpiéhj, os donos de animais, das caças, para a festa, para reivindicar deles mais bebeéhj (queixadas) para a aldeia. Mas há algo mais por trás disso. Não era só para isso que a festa era realizada. Era convocada pela pessoa que tinha relacionamento respeitoso e harmônico com seu povo. Quando se sentia só, sentia falta, saudade do seu povo, essa pessoa precisava trazer esse seu povo para visitá-lo. Para isso, ele criava uma estratégia: convocava e organizava um encontro, uma festa como meio de atração 
e de reunir as pessoas para fortalecer os laços de união. Assim, o povo ficava unido e organizado para vencer obstáculos que viessem em qualquer momento, seja no trabalho ou na guerra. Para isso, o madjaj organizava essa festa. A festa, assim, pode ser compreendida como a base de organização social do povo Ikólóéhj. A pessoa que realizava as festas ganhava a confiança do seu povo e se tornava uma pessoa importante para eles, uma liderança de referência para sua comunidade. $A$ partir disso, ele, o madjaj, era bem falado e ganhava respeito.

A festa era um momento de encontro, de se organizar e criar alianças entre as pessoas e entre estas e os seres divinos. Deste modo os Ikólóéhj eram organizados, todos se entendiam harmonicamente. A festa toda é pautada em momentos de reciprocidade e solidariedade. Na festa ocorria a reciprocidade quando os caçadores traziam carnes moqueadas e por sua vez consumiam a chicha do madjaj. Entre os homens e os seres espirituais também ocorria reciprocidade, pois os Garpiéhj doavam as caças para o povo e equilibravam as estações (tempo seco e tempo chuvoso) e em troca recebiam chicha, cantavam e dançavam incorporados no vạvạ́h. Enquanto o vạvạ́h recebia estes "visitantes", várias canções, que até então eram desconhecidas na comunidade, passavam a ser entoadas por ele, pois eram os próprios Garpiéhj que cantavam através do vaváh. A música é cantada através de uma língua que não é falada na aldeia. Isso comprova que realmente existe sociedade do além, os seres do mundo sobrenatural, os seres divinos.

\section{Sobre o ritual e a vida atual dos ikólóehj}

A festa constituía também um momento de repassar a ética e a educação Ikólóehj. Era durante a festa que o povo tomava conhecimento sobre os seres espirituais e como devia se relacionar com eles. Participando da festa, percebendo, vendo o que estava acontecendo, é que o pessoal ia adquirindo conhecimento sobre os Tìh, que existe Tìh da natureza e da sobrenatureza. É a partir disso que as pessoas aprendiam a respeitar os Tìh. Os Tì são os donos das coisas como, por exemplo, o Djàvpè Tìh. Djàvpè é a taboca utilizada para fazer a ponta da flecha, o Djàvpè Tì é o ser dono desta taboca. Para coletar as tabocas a fim de confeccionar a flecha, é preciso comunicar com o vaváh para que ele peça autorização ao dono do djàvpè que é o Djàvpè Tìh. Da mesma forma, na festa do Garpiéhj Náe, é o vavaáh quem convida e traz os donos das criações para reivindicar a caça para o povo e criar parceria e aliança com eles. "O Tìh está presente em tudo na natureza, nas florestas, nas águas, no céu, e nas árvores" (SÉHVBIRÓHV, 2014, entrevista). 
As pessoas aprendem que quando se danifica a natureza está se danificando a casa dos Tih, por exemplo, quando os seres humanos constroem uma barragem está sendo destruída a casa do Gojánéhj que é o dono das águas; quando se derruba a floresta está se destruindo a casa do Zagapóhj que é o dono das matas (SÉHVBIRÓHV, 2014, entrevista).

Muitas vezes, os indígenas são questionados porque tem muita terra, mas as pessoas que dizem isso não se aprofundam nesse tipo de conhecimento. Para nós, a terra que temos hoje é uma extensão mínima. Já tivemos muitas, mas não era bem nossas. É o bem comum de todos que Gorá (criador) preparou para nós. Temos que entender por que nós, os indígenas, necessitamos de muita floresta, muita terra. A floresta é a nossa inspiração. Existe necessidade de ter tudo isso porque nossa vida está ligada nela. Acreditamos no Tì da floresta, da água e precisamos preservar o abrigo desses Tìh, para não provocar a ira desses seres que são nossos parceiros e com quem vivemos interligados. São nossos parceiros, mas a paciência deles tem limites. Eles têm poder que os seres humanos não chegam a controlar. Como por exemplo, os espíritos das águas que provocam grandes inundações que os brancos não conseguem entender. Nós não estamos sozinhos aqui na terra, temos ligação com esses seres que podem nos ajudar enviando caça, nos proteger de outros espíritos e assim por diante. Até criamos casamento entre os seres sobrenaturais e os homens. Um exemplo é o do vavaáh Xípo Ségóhv, que formou família com uma mulher Olixixia, ser espiritual, hora visível, hora invisível, que protege o povo Ikólóehj Gavião do ataque de outros seres espirituais, como os Zerebajéhj, que os Ikólóehj acreditavam que eram outros povos que se transformavam em um ser espiritual do mal. Segundo Antônio Alía,

Isso acontecia antigamente. Mas isso também acontece atualmente. Ontem mesmo, assoviavam os evòréhj [espíritos aliados do vaváh], mas a gente não sabe o que está acontecendo, somente as pessoas que entendem sabem 0 que está acontecendo (ALÍA, 2015, entrevista).

Atualmente não há vạvạhej que podem realizar a festa Garpiéhj Náe entre os Ikólóehj Gavião. Por isso, acredito que seja possível que o contato com esses seres enfraqueceu prejudicando, desta forma, a aliança entre os Garpiéhj e os Ikólóehj. No entanto, é necessário aprofundar uma pesquisa sobre isso para afirmar com certeza. Um dos motivos que acredito ter levado ao enfraquecimento desta aliança com os Garpiéhj é a influência de uma religião externa, o cristianismo, que tomou o espaço da religião Ikólóehj que antes era praticada com frequência e hoje é praticada raramente. $O$ ensinamento dos missionários da Missão Novas Tribos do Brasil considerou essa prática do vavaáh como um trabalho maligno. Os seres espirituais Ikólóehj são desprezados e demonizados nas pregações da igreja. 
Atualmente, o vaváh não exerce abertamente suas funções por causa do desprezo que sofre por parte da comunidade que se converteu a esta religião externa.

Esta religião ao invés de estimular a união da comunidade para o fortalecimento da sua organização social, que era o papel das festas, leva ao individualismo e à divisão do povo. As pessoas que não se convertem são criticadas pelo grupo. A festa do Garpiéhj Náe, pelo contrário, procurava unir a maior quantidade de pessoas possível onde ninguém era desvalorizado e excluído. Desta maneira, a união do povo e a luta pela sobrevivência eram mais fortes e as práticas culturais eram mais preservadas. A luta pela terra era mínima para o povo. Nos dias atuais, o povo Ikólóéhj não tem mais o mesmo Tì que eles tinham no passado, as forças, o espírito guerreiro que seus ancestrais possuíam. Até mesmo os Zavidjajéhj, as lideranças tradicionais, têm, cada vez mais, se aproximado da igreja. A igreja na aldeia, por um lado, pode ser prejudicial para a identidade cultural do povo Ikólóéhj se ela não der espaço para a promoção deste tipo de festa.

A festa era o momento em que os seres espirituais marcavam sua presença na comunidade Ikólóehj, para se reafirmar como aliados protetores deste povo. As festas eram ocasião de aprendizagens e reprodução dessa prática pelas novas gerações. No entanto, as práticas das festas e da religião tradicional não acontecem mais como antes e vão, gradativamente, deixando de ser realizadas, sendo que a festa Garpiéhj Náe já não acontece há pelo menos trinta anos. 